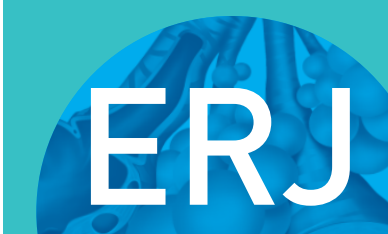

open

research

\title{
Pro-tumoural CXCL10/CXCR3-A autocrine loop in invasive mucinous lung adenocarcinoma
}

\author{
Michaël Duruisseaux ${ }^{1}$, Nathalie Rabbe ${ }^{1,3}$, Martine Antoine ${ }^{1,2}$, Thibault Vieira ${ }^{1,3}$, \\ Virginie Poulot ${ }^{1,4}$, Jacques Cadranel ${ }^{1,3}$ and Marie Wislez $z^{1,3}$
}

Affiliations: 'Sorbonne Universités, UPMC University Paris 06, GRC n04, Theranoscan, F-75252, Paris, France. ${ }^{2}$ Service d'Anatomie Pathologique, AP-HP, Hôpital Tenon, Paris, France. ${ }^{3}$ Service de Pneumologie, AP-HP, Hôpital Tenon, F-75970, Paris, France. ${ }^{4}$ Plateforme de Génomique des Tumeurs Solides, AP-HP, Hôpital Tenon, Paris, France.

Correspondence: Marie Wislez, Service de Pneumologie, Hôpital Tenon, 4 Rue de la Chine, F-75970, Paris. E-mail: marie.wislezQaphp.fr

ABSTRACT Invasive mucinous adenocarcinoma (IMA) is a mucinous variant of lepidic predominant lung adenocarcinoma (LPA) and associated with a worse prognosis. We postulated that cytokine expression would enable us to differentiate IMA from LPA in terms of prognosis and acquisition of pro-tumoural capacities.

A 30-cytokine panel was assessed in bronchoalveolar lavage fluids (BALF) from IMA ( $\mathrm{n}=38$ ), LPA $(n=25)$ and control samples $(n=7)$. We investigated the expression of differentially expressed cytokines and splice variants of their receptors in surgical samples. The presence of EGFR and KRAS mutations were determined. We also examined the expression of cytokines and splice variants of their receptors in different cell lines, exploring their functional impact on signalling pathways, proliferation and migration.

Only C-X-C motif chemokine 10 (CXCL10) was differentially expressed, namely overexpressed in IMA BALF compared with LPA. CXCL10 overexpression in BALF was linked to a worse prognosis. In surgical samples, CXCL10 and its receptor C-X-C motif chemokine receptor 3 (CXCR3) were overexpressed in IMA compared to LPA. A pro-tumoural CXCR3-A splice variant was overexpressed in IMA, suggesting a CXCL10/CXCR3-A autocrine loop in IMA. CXCL10 and CXCR3 expression were not correlated with EGFR or KRAS status. CXCL10 up-regulated CXCR3-A expression, Erk1/2 phosphorylation and enhanced migration in the mucinous $\mathrm{H} 2228$ cell line.

CXCL10/CXCR3-A may play a pro-tumoural role in IMA via an autocrine mechanism.

@ERSpublications

Invasive mucinous lung adenocarcinoma derived pro-tumoural advantages by means of a CXCL10/CXCR3-A autocrine loop http://ow.ly/2Gjj308QxwK

Cite this article as: Duruisseaux M, Rabbe N, Antoine M, et al. Pro-tumoural CXCL10/CXCR3-A autocrine loop in invasive mucinous lung adenocarcinoma. ERJ Open Res 2017; 3: 00047-2016 [https://doi.org/10.1183/23120541.00047-2016].

This article has supplementary material available from openres.ersjournals.com

Received: March 302016 | Accepted after revision: Jan 022017

Support statement: M. Duruisseaux is a doctoral fellow funded by Fonds de dotation Recherche en Santé Respiratoire 2010, AgiràDom and Comité des maladies respiratoires (COMARES) de l'Isère. T. Vieira is a doctoral fellow funded by Fonds de dotation Recherche en Santé Respiratoire 2011. This study also received support from Subvention 2010 et 2011 Leg Poix-La Chancellerie des Universités de Paris and ITMO Cancer 2012 Institut National du Cancer Plan Cancer 2009-2013 "Modèles de tumeurs spontanées chez l'animal pour la recherche translationnelle en cancérologie". Funding information for this article has been deposited with the Crossref Funder Registry.

Conflict of interest: None declared.

Copyright $\odot$ ERS 2017. This article is open access and distributed under the terms of the Creative Commons Attribution Non-Commercial Licence 4.0. 


\section{Introduction}

Lung adenocarcinomas are the most common histological type of non-small cell lung cancer (NSCLC) [1]. Invasive adenocarcinomas consist of a mixture of different histological patterns, termed lepidic, acinar, solid, papillary or micropapillary [2]. Lepidic predominant adenocarcinoma (LPA) is characterised by predominant "lepidic growth", meaning proliferations of bland pneumocyte cells growing along the pre-existing alveolar structure. Compared to other NSCLC types, LPA less frequently affects smokers and there is no sex bias [3]. While LPA is typically a non-mucinous adenocarcinoma, a mucinous variant does exist, termed invasive mucinous adenocarcinoma (IMA) [2]. In IMA, tumoural cells have the morphology of goblet or columnar cells, with abundant intracytoplasmic mucin and small, basally located nuclei; they usually appear as well-differentiated cells. IMA is associated with a worse prognosis than other NSCLC subtypes, probably due to its aerogenous spreading, which accounts for the common multicentric and bilateral lung involvement observed in these cases [4-14], and the lack of effective treatment at this stage. Patients with IMA usually present with respiratory signs at diagnosis. In cases of relapse following surgery, typically the lungs are exclusively involved, and patients usually die of respiratory failure in advanced-stage disease $[3,14]$.

The molecular mechanisms of LPA and IMA are not yet fully understood. EGFR mutations are associated with LPA, whereas KRAS mutations and oncogenic fusion genes appear to drive IMA [14-19].

This study sought to identify the cytokines or chemokines that are differentially expressed in LPA and IMA and their role in tumoural promotion.

\section{Materials and methods}

Clinical samples and ethical considerations

Between January 1992 and July 2010, 92 patients with LPA and IMA were diagnosed in our chest department. The diagnosis was reviewed by a lung pathologist (M.A.) based on the 2011 International Association for the Study of Lung Cancer/American Thoracic Society/European Respiratory Society lung adenocarcinoma classification [2]. Disease stage was classified according to the seventh edition of the international TNM Classification of Malignant Tumours [20]. Follow-up data were recorded until death. Surgical resection was performed in 54 patients, with surgical paraffin-embedded samples available for all 54 patients, and frozen surgical samples for 14 patients.

Bronchoalveolar lavage fluid (BALF) was used as a diagnostic tool, as previously described [21]. Following diagnosis, the remaining BALF was spun and the supernatant aseptically separated and stored at $-80^{\circ} \mathrm{C}$. Frozen BALF supernatant samples were available for 70 patients. Information about control individuals has been provided in the supplementary methods.

All patients signed a research approval informed consent form. All informed consent forms were collected and stored in the Tenon Pathology Department (Tumorothèque des Hôpitaux Universitaires de l'Est Parisien, Tenon Hospital). This study was approved by our hospital's ethics human research committee.

\section{Cell lines and culture conditions}

Human H358, H322, A549, H2228, H441 and H1650 lung adenocarcinoma cell lines and the human lung primary fibroblasts (CCD16-Lu) were purchased from the American Type Culture Collection (ATCC, Manassas, VA, USA) and the human lung microvascular endothelial cells (HMVEC-L) from Lonza (Levallois, France). Details of the cell lines and culture conditions have been provided in the supplementary methods. Morphologic, phenotypic and molecular characteristics of the cell lines are summarised in supplementary table S1.

\section{Chemokine and cytokine quantification in bronchoalveolar lavage fluid}

Chemokine and cytokine concentrations in BALF supernatants were quantified using Bio-Plex multiplex bead-based assays by means of Bio-Plex Pro ${ }^{\text {TM }}$ Human Cytokine 27-Plex Immunoassay and three individual assays for human VCAM-1, growth regulated protein- $\alpha$ (GRO- $\alpha)$ and hepatocyte growth factor (HGF) (Bio-Rad Laboratories, Marnes-la-Coquette, France). For each cytokine calibration curve, eight standards were used. Data acquisition and analysis were completed using the Bio-Plex 200 System with workstation Bio-Plex ManagerTM software Version 5.0 (Bio-Rad Laboratories). Each condition was performed in duplicate.

\section{Immunohistochemistry}

Formalin-fixed, paraffin-embedded 3- $\mu \mathrm{m}$ tissue sections from surgical specimens were used for C-X-C motif chemokine 10 (CXCL10) and C-X-C motif chemokine receptor 3 (CXCR3) immunohistochemical (IHC) studies. The details of the IHC protocol have been provided in the supplementary methods. 
EGFR and KRAS gene mutations and ALK rearrangement analysis

For each formalin-fixed, paraffin-embedded specimen, a $3-\mu \mathrm{m}$ tissue section was stained with hematoxylin and eosin and examined by light microscopy to determine the presence of tumour cells. After isolating the DNA (QIAamp DNA mini kit, Qiagen, Courtaboeuf, France) from three 20- $\mu \mathrm{m}$ tissue sections, EGFR 18-21 and KRAS 2 exons were amplified and sequenced in both directions, as previously described [22]. Sequenced data were then analysed using SeqScape software. Immunostaining of the ALK fusion protein was performed on 3- $\mu \mathrm{m}$ tissue sections and processed by a Benchmark Ventana staining module (Ventana Medical Systems, Roche Diagnostics, Meylan, France) using the primary monoclonal antibody against ALK (Clone 5A4, Ab 17127; Abcam, Paris, France) diluted at 1:50 for $2 \mathrm{~h}$ at $37^{\circ} \mathrm{C}$, as previously described [23]. A positive external control was performed, using an adenocarcinoma specimen that heen previously validated for $A L K$ rearrangement by fluorescent in situ hybridisation (FISH). The percentage of positive cells was evaluated and staining scores were assessed as follows: 0, no staining; 1+, faint cytoplasmic staining; $2+$, moderate cytoplasmic staining; and 3+, intense granular cytoplasmic staining. The presence of $10 \%$ of cells stained with an intensity of $\geqslant 2$ was considered as positive staining. Specimens with a positive score were tested for ALK rearrangement by FISH. Briefly, FISH was performed on unstained $4-\mu \mathrm{m}$ formalin-fixed, paraffin-embedded tumour-tissue sections using an $A L K$ break-apart probe set (Vysis LSI ALK Dual Color, Break Apart Rearrangement Probe; Abbott Molecular, Rungis, France) and a paraffin-pretreated reagent kit (Vysis, Abbott Molecular) according to the manufacturer's instructions. Tumour tissues were considered ALK-FISH positive if $>15 \%$ of the cells showed split red and green signals and/or single red signals.

RNA and quantitative reverse transcriptase PCR

The details of the quantitative reverse transcriptase ( $\mathrm{qRT}$ )-PCR protocol have been provided in the supplementary methods.

Western blotting analysis

The details of western blotting protocol have been provided in the supplementary methods.

\section{ELISA assays}

CXCL10 expression was determined in the cell supernatants using ELISA detection kits, in accordance with the manufacturer's instructions (R\&D Systems, Minneapolis, MS, USA).

\section{Cell migration assay and cell proliferation assay}

The details of the cell migration assay (3-[4, 5-dimethylthiazol-2-yl]-2, 5-diphenyltetrazolium bromide (MTT) assay) protocol have been provided in the supplementary methods.

\section{Statistical analysis}

Our results are expressed as mean \pm SEM. For quantitative variables, comparisons were made using the Mann-Whitney and Kruskal-Wallis non-parametric tests. For qualitative variables, the Chi-squared test was used for comparisons and Spearman's rank correlation coefficient (rho) for correlation analysis. A p-value $<0.05$ was considered statistically significant.

Survival time was defined as the time from diagnosis to death or the cut-off date, fixed at August 2011. Survival rates were calculated by means of the Kaplan-Meier method and survival curves compared using the log-rank test. Quantitative variables were coded as dichotomous (present or absent and high or low level), and the cut-off values represented the means of sampling distribution. Multivariate analysis was performed by means of Cox's multiple regression models. The lack of co-linearity between variables was verified using the Chi-squared test. Variables with a p-value $<0.1$ on univariate analysis were tested in the multivariate Cox model, with the final model chosen using a backward stepwise variable selection process based on the $\mathrm{p}$-value as a candidate predictor. The threshold of significance was set at $\mathrm{p}<0.05$. All findings were processed using SPSS 20.0 software (IBM Corporation, Armonk, NY, USA).

\section{RESULTS}

Clinical, pathological and molecular characteristics of the patients

Clinical and molecular findings are summarised in table 1. Five mixed cases of IMA showing mucinous and non-mucinous patterns were identified in surgical samples. All driver oncogenes detected were mutually exclusive. As shown in table 2, never smokers were more common among patients diagnosed with an IMA $(\mathrm{p}=0.032)$ than an LPA. There was no difference in age at diagnosis, sex, performance status at diagnosis and clinical stage according to histological status. EGFR mutations were exclusively detected in LPA and there was a trend for a higher proportion of KRAS-positive tumours in IMA compared to LPA $(30 \%$ versus $17 \%$ of those with available data, $\mathrm{p}=0.277$ ) (table 2 ). 


\section{TABLE 1 Clinical, pathological and molecular characteristics of the patients}

\begin{tabular}{|c|c|}
\hline & Patients \\
\hline Subjects $n$ & 92 \\
\hline Age years (mean \pm SEM) & $65 \pm 1$ \\
\hline \multicolumn{2}{|l|}{ Sex } \\
\hline Female & $42(46)$ \\
\hline Male & $50(54)$ \\
\hline \multicolumn{2}{|l|}{ Smoking status } \\
\hline Never smoked & $25(27)$ \\
\hline Former or current & 67 (73) \\
\hline \multicolumn{2}{|l|}{ Performance status } \\
\hline 0 & $60(65)$ \\
\hline$>0$ & 30 (33) \\
\hline MD & $2(3)$ \\
\hline \multicolumn{2}{|l|}{ Histological status } \\
\hline Invasive mucinous adenocarcinoma & 49 (53) \\
\hline Invasive lepidic predominant adenocarcinoma & 36 (39) \\
\hline Cytological diagnosis & $7(8)$ \\
\hline \multicolumn{2}{|l|}{ Stage } \\
\hline 1 & $15(16)$ \\
\hline II & 17 (18) \\
\hline III & $7(8)$ \\
\hline IV & $53(58)$ \\
\hline \multicolumn{2}{|l|}{ EGFR mutation } \\
\hline Positive & $8(9)$ \\
\hline Negative & $65(71)$ \\
\hline MD & $19(20)$ \\
\hline \multicolumn{2}{|l|}{ KRAS mutation } \\
\hline Positive & $18(20)$ \\
\hline Negative & $55(60)$ \\
\hline MD & $19(20)$ \\
\hline \multicolumn{2}{|l|}{$A L K$ rearrangement } \\
\hline Positive & $1(1)$ \\
\hline Negative & 72 (79) \\
\hline$M D$ & $19(20)$ \\
\hline
\end{tabular}

Cytokine expression in bronchoalveolar lavage fluid

We assessed chemokine and cytokine concentrations in BALF supernatants from patients $(n=70)$ and controls $(\mathrm{n}=7)$ by performing multiplex cytokine assays. Of the 30 proteins examined, 10 were present in higher concentrations in patients (CXCL10, monocyte chemoattractant protein-1 (MCP-1), macrophage inflammatory protein-1 $\beta$ (MIP-1 $\beta$ ), regulated on activation, normal $\mathrm{T}$ cell expressed and secreted (RANTES), hepatocyte growth factor (HGF), vascular endothelial growth factor (VEGF), interleukin (IL)-6, IL-8, granulocyte-colony stimulating factor (G-CSF) and interferon- $\gamma$ (IFN $\gamma$ )) (table 3). Only CXCL10 was differentially expressed when comparing IMA with LPA (figure 1A). CXCL10 concentration was higher in IMA compared to LPA and controls $\left(9714 \mathrm{pg} \cdot \mathrm{mL}^{-1} \pm 1693\right.$ versus $3716 \mathrm{pg} \cdot \mathrm{mL}^{-1} \pm 872$ versus $504 \mathrm{pg} \cdot \mathrm{mL} \pm 149$, respectively; $\mathrm{p}=0.004$ ).

\section{CXCL10 overexpression and survival}

On univariate analysis, a high level of CXCL10 concentration was associated with shorter survival (high versus low: 13 versus 40 months, $\mathrm{p}=0.016$ ) (figure $1 \mathrm{~B}$ ), worse performance status $(\mathrm{p}=0.004)$ ), and stage IV disease ( $\mathrm{p}=0.001$ ) (supplementary table $\mathrm{S} 2$ ). On multivariate analysis, only stage IV disease was associated with shorter survival (supplementary table S2).

\section{Expression of CXCL10 and CXCR3 in surgical samples}

We analysed 54 surgical samples from IMA $(n=27)$ or LPA $(n=27)$. Our pathological findings have been outlined in figure $1 \mathrm{C}$, demonstrating that CXCL10 was expressed in the cytoplasm of tumour cells in 42 patients (78\%). CXCL10 expression was uncommon in mononuclear stromal cells. CXCL10 was more commonly expressed in IMA (25 out of 27 patients, 93\%) than in LPA (17 out of 27 patients, 63\%; $\mathrm{p}=0.009)$. CXCL10 staining scores were significantly higher in IMA (110 \pm 14$)$ than in LPA $(24 \pm 2 ; \mathrm{p}<0.001)$. 


\begin{tabular}{|c|c|c|c|}
\hline & $\begin{array}{l}\text { Invasive mucinous } \\
\text { adenocarcinoma }\end{array}$ & $\begin{array}{l}\text { Lepidic predominant } \\
\text { adenocarcinoma }\end{array}$ & p-value \\
\hline Subjects $\mathrm{n}$ & 49 & 36 & \\
\hline Age years (mean士sem) & $65 \pm 2$ & $64 \pm 2$ & $0.74^{\#}$ \\
\hline Sex & & & $0.083^{\text {I }}$ \\
\hline Female & 19 (39) & $21(58)$ & \\
\hline Male & $30(61)$ & $15(42)$ & \\
\hline Smoking status & & & $0.032^{\pi}$ \\
\hline Never smoked & 19 (39) & $6(17)$ & \\
\hline Former or current & $30(61)$ & $30(83)$ & \\
\hline Performance status & & & $0.336^{\pi}$ \\
\hline 0 & $32(65)$ & $27(75)$ & \\
\hline$>0$ & $16(33)$ & $8(22)$ & \\
\hline MD & $1(2)$ & $1(3)$ & \\
\hline Stage & & & $0.514^{\text {9 }}$ \\
\hline I & $8(16)$ & $11(30)$ & \\
\hline II & $12(24)$ & 7 (19) & \\
\hline III & $5(10)$ & $3(8)$ & \\
\hline IV & $24(50)$ & $15(43)$ & \\
\hline EGFR mutation & & & $<0.001^{\pi}$ \\
\hline Positive & $0(0)$ & $8(22)$ & \\
\hline Negative & $44(90)$ & $21(58)$ & \\
\hline MD & $5(10)$ & $7(20)$ & \\
\hline \multicolumn{4}{|l|}{ KRAS mutation } \\
\hline Positive & $13(27)$ & $5(13)$ & $0.277^{\text {ๆ }}$ \\
\hline Negative & $31(63)$ & $24(67)$ & \\
\hline MD & $5(10)$ & $7(20)$ & \\
\hline$A L K$ rearrangement & & & 0.999 ? \\
\hline Positive & $1(2)$ & $0(0)$ & \\
\hline Negative & $42(86)$ & $30(83)$ & \\
\hline$M D$ & $6(12)$ & $6(17)$ & \\
\hline
\end{tabular}

CXCR3 was expressed in the cytoplasmic membrane and in the cytoplasm of tumour cells in 24 patients (44\%). CXCR3 was more frequently expressed in IMA (20 out of 27 patients, $74 \%$ ) than in LPA (4 out of 27 patients, $15 \%$; $<<0.001)$. CXCR3 staining scores were significantly higher in IMA $(69 \pm 5)$ than in LPA $(17 \pm 2 ; \mathrm{p}=0.047)$.

CXCL10 staining score strongly correlated with CXCR3 staining score $(r=0.527, p<0.001$; figure $1 D$. Concomitant expression of CXCL10 and CXCR3 in surgical samples was significantly more common in IMA than in LPA (66\% versus 22\%, $\mathrm{p}=0.002$ ). CXCR3-positive tumours exhibited higher concentrations of CXCL10 in the BALF supernatants than those detected in CXCR3-negative tumours ( $\mathrm{p}=0.005$, supplementary figure S1). CXCL10 and CXCR3 expression did not notably differ in cases of IMA showing mixed mucinous and non-mucinous patterns as compared to the overall population (data not shown).

We examined the expression of the CXCR3-A and CXCR3-B mRNA splice variants in frozen surgical samples from IMA $(n=7)$ and LPA $(n=7)$ using qRT-PCR. CXCR3-A and CXCR3-B mRNA was detected in all samples. CXCR3-A mRNA was significantly overexpressed in IMA (2691 \pm 450$)$ compared to LPA (1227 $\pm 191 ; \mathrm{p}=0.022$ ) (supplementary figure S2).

\section{Relationship between EGFR and KRAS status and CXCL10/CXCR3 expression}

CXCL10 expression in BALF and surgical samples as well as CXCR3 expression in surgical samples was comparable in EGFR-positive or EGFR-negative tumours and in KRAS-positive or KRAS-negative tumours (supplementary figure S3). Neither EGFR status nor KRAS status was associated with concomitant expression of CXCL10 and CXCR3 in surgical samples (data not shown).

\section{Functional study of CXCL10/CXCR3-A in cell lines}

CXCL10 and CXCR3 expression was assessed in mucinous (H2228, H358, H441) and non-mucinous (H322, H1650, A549) lung adenocarcinoma cell lines. As shown in figure 2, lung adenocarcinoma cell 
TABLE 3 Concentrations of chemokines and cytokines in bronchoalveolar lavage supernatant of the patients and controls based on multiplex antibody bead assay

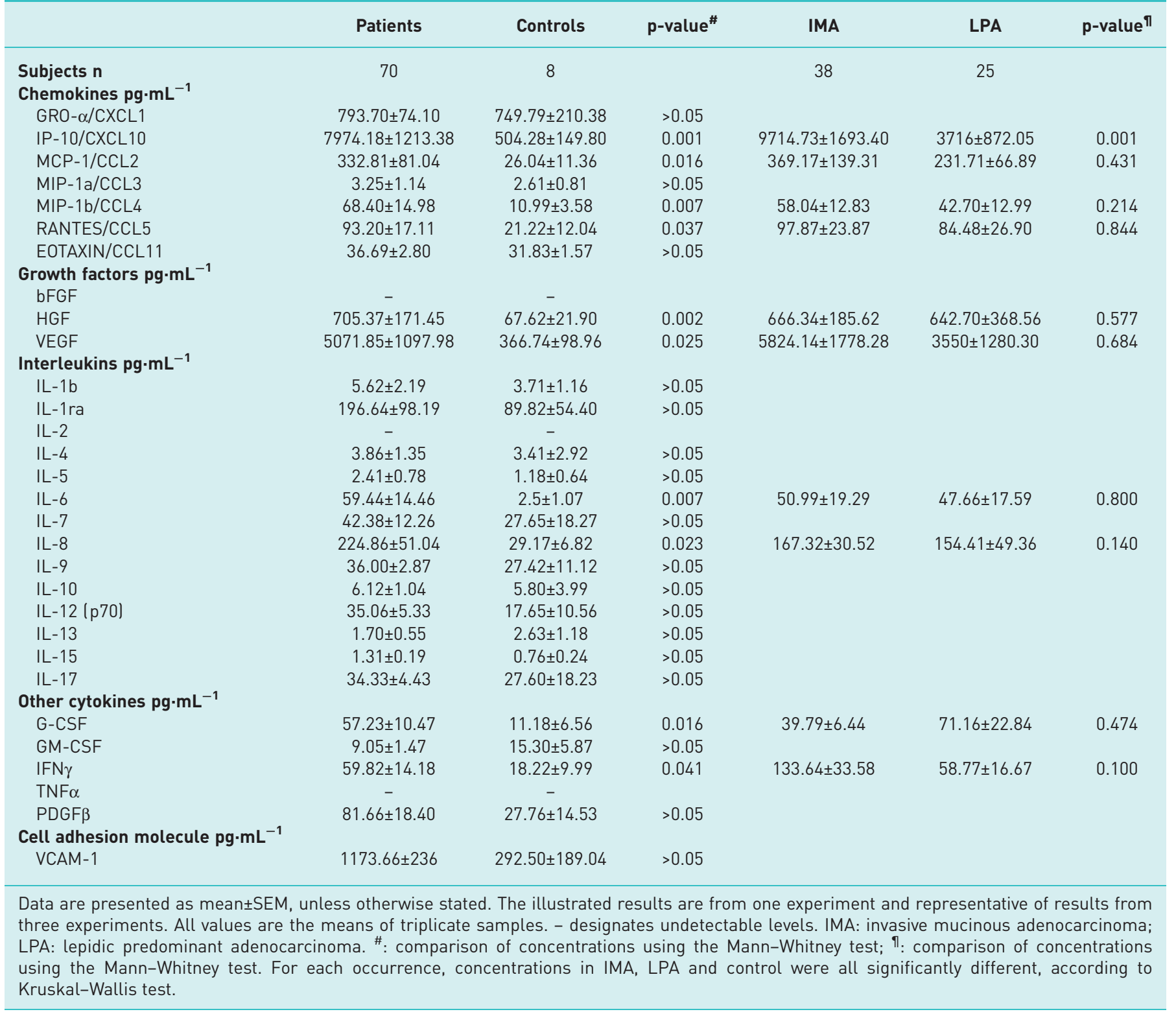

lines did not secrete CXCL10 constitutively. Because CXCL10 has been shown to be up-regulated by IFN $\gamma$, we exposed the cell lines to recombinant human (rh) IFN $\gamma$. This induced a potent CXCL10 secretion from these cells, whether they were mucinous or non-mucinous (figure 2A) [24]. CXCR3 was expressed in all the cell lines at basal state (figure 2B). At basal state, CXCR3-A and CXCR3-B mRNA splice variants were expressed in the cell lines (figure 3). We next analysed whether CXCL10 regulated CXCR3-A and CXCR3-B mRNA expression. After exposure to rhCXCL10 for $24 \mathrm{~h}$ at $250 \mathrm{ng} \cdot \mathrm{mL}^{-1}$, CXCR3-A mRNA expression was up-regulated in $\mathrm{H} 2228$ cells with a 25-fold increased induction compared to basal state, whereas CXCR3-B mRNA expression was not significantly modified (figure 3). The addition of rhCXCL10 did not significantly influence CXCR3-A or CXCR3-B mRNA splice variant expression in other cell lines.

To determine whether CXCL10 affects signalling pathways, cell lines were exposed to rhCXCL10 for $24 \mathrm{~h}$ at concentrations ranging from 50 to $250 \mathrm{ng} \cdot \mathrm{mL}^{-1}$. As shown by western blotting, rhCXCL10 induced up-regulation of Erk1/2 phosphorylation in H2228, though no effect was observed in the intracellular signalling in other cell lines (supplementary figure S4).

We assayed the ability of CXCL10 to induce H2228 and H322 migration. Cell lines were exposed for 24 or $48 \mathrm{~h}$ to different concentrations of rhCXCL10 in a Boyden chamber. The number of migrating cells was 

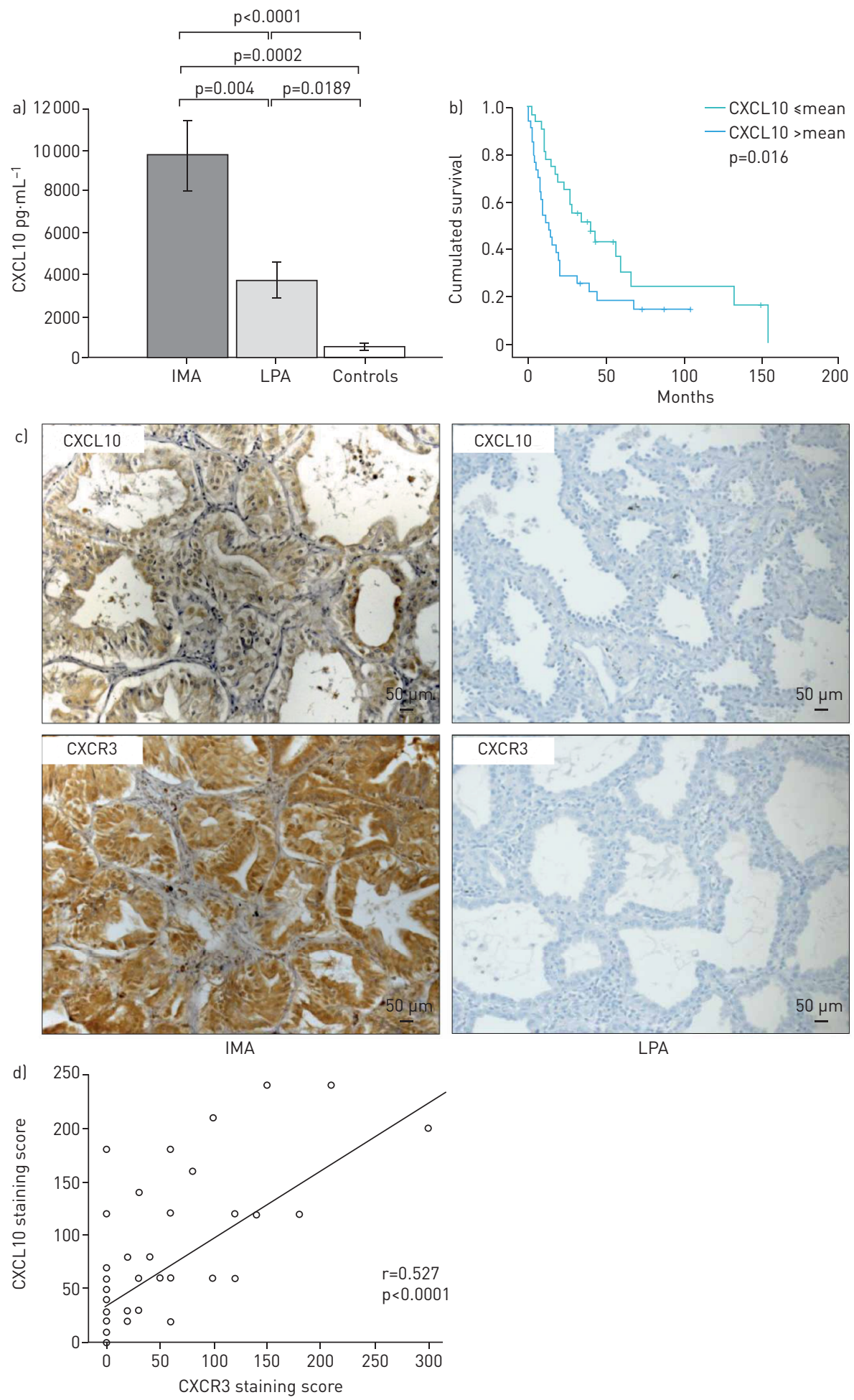

FIGURE 1 CXCL10/CXCR3 overexpression in invasive mucinous adenocarcinoma (IMA). CXCL10 concentration was assessed in 70 bronchoalveolar lavage fluid (BALF) supernatants from patients by an antibody magnetic bead assay (Bioplex® System). Each sample was assessed in duplicate. a) CXCL10 concentrations in BALF supernatants from IMA ( $n=38$ ), lepidic predominant lung adenocarcinoma (LPA; $n=25)$ and controls ( $n=7)$. p-values reflect Kruskal-Wallis test or Mann-Whitney test. Data displayed as means with SEM indicated by whiskers. b) Survival curve of patients with high and low CXCL10 levels in BALF supernatants (log rank test). c) CXCL10 and CXCR3 staining (brown) in IMA and LPA. d) Correlation between CXCL10 and CXCR3 staining scores (Spearman's rho test). 
a)
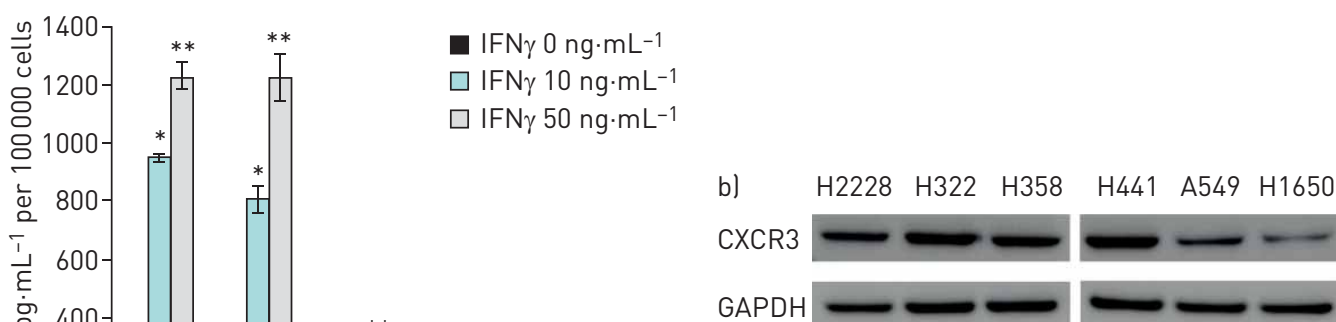
cell line supernatants assessed by ELISA, after exposure to recombinant human interferon- $\gamma$ (IFN $\gamma$ ) (0, 10 or $50 \mathrm{ng} \cdot \mathrm{mL}^{-1}$ ) (Mann-Whitney test). Each sample was assessed in triplicate and results are representative of three independent experiments. Data displayed as means with SEM indicated by whiskers. *: p<0.05; **: $p<0.005$; difference between stimulated and unstimulated cells. b) Determination of CXCR3 expression by western blotting in cell lines. Representative of three independent experiments performed for each cell line.

then evaluated, revealing that rhCXCL10 induced the migration of H2228, yet not H322, cells in a timeand dose-dependent manner (supplementary figure S5).

CXCL10 did not affect cell growth in either the H2228 or H322 cell lines, as assessed by MTT assay (data not shown).

\section{Discussion}

Our findings indicate that IMA is characterised by overexpression of CXCL10 and its receptor splice variant CXCR3-A. This could indicate that CXCL10/CXCR3-A act as an autocrine loop in IMA, being involved in the acquisition of pro-migratory capacities.

CXCL10 is a member of the subfamily of IFN $\gamma$-inducible non-ELR CXC chemokines and is expressed by a large variety of human cell types [24]. It was initially described as a major chemoattractant for monocytes, activated $\mathrm{T}$ cells and natural killer cells. Here, we have proven the existence of tumour expression of CXCL10/CXCR3 in a specific subtype of adenocarcinoma. We have additionally demonstrated that CXCL10 overexpression is linked to poorer survival, suggesting it has a pro-tumoural capacity. Numerous studies have reported the dual role played by CXCL10 and its receptor CXCR3 in malignancy. In several human cancer models, CXCL10/CXCR3 is involved in the anti-tumoural effects of stromal cells, such as angiostatic mechanisms or the recruitment of CXCR3-positive mononuclear cells involved in immune responses [24-26]. Conversely, a number of recent works have demonstrated that CXCL10/CXCR3 can promote tumour progression in natural killer nasal lymphomas, colorectal cancers, breast cancers or myelomas by stimulating the pro-migratory or pro-metastatic capacities of tumour cells themselves via autocrine or paracrine loops [27-33]. CXCR3 expression in metastatic colorectal cancer cells is known to be up-regulated and associated with worse survival. The CXCL10/CXCR3 axis promotes invasive and metastatic capacities.

The two major splice variants CXCR3-A and CXCR3-B have a biological impact, with CXCR3-A shown to possess pro-tumoural capacities while CXCR3-B leads to the inhibition of DNA synthesis and the apoptosis of tumour cells $[34,35]$. We found that these splice variants of CXCR3, namely "anti-tumoural" CXCR3-B and "pro-tumoural" CXCR3-A, were differentially expressed in IMA. There was increased expression of CXCR3-A in IMA compared to that in LPA. In addition, following exposure to CXCL10, CXCR3-A expression was up-regulated in the mucinous H2228 cell line, whereas CXCR3-B expression was not modified. We therefore used H2228 as a model of a functional CXCL10/CXCR3-A autocrine loop, and $\mathrm{H} 322$ as a negative control. CXCL10/CXCR3-A stimulated cell migration in the mucinous H2228 cell line, yet not in the non-mucinous H322, which primarily expressed CXCR3-B. We suggest that CXCL10/ CXCR3-A up-regulation is a specific feature of IMA. We postulate that inhibiting the CXCL10/CXCR3 axis could present a therapeutic opportunity to avoid lung cancer spreading in IMA. AMG487 is a small-molecular-weight antagonist of CXCR3 and has exhibited the potential to inhibit tumour metastasis in murine models of breast cancer and osteosarcoma [32]. Furthermore, several CXCL10 inhibitors are currently subject to clinical investigation in primary biliary cirrhosis and inflammatory diseases [36, 37].

Published data in lepidic adenocarcinoma show that EGFR activating mutations are restricted to LPA whereas KRAS mutations are more common in IMA [3]. The molecular characteristics of our cohort are 

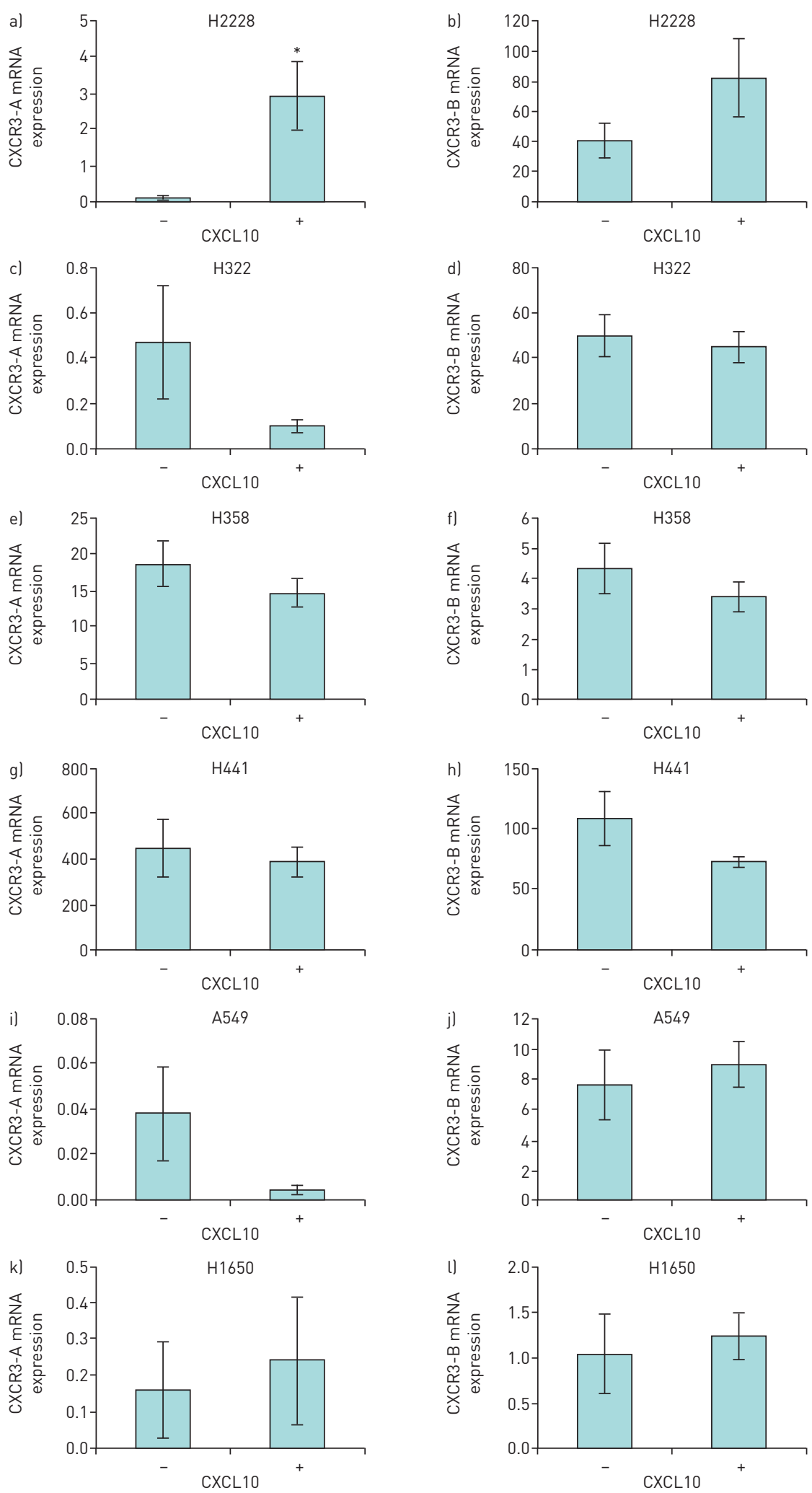

FIGURE 3 CXCL10 up-regulates CXCR3-A splice variant expression in the mucinous H2228 cell line. CXCR3-A and CXCR3-B mRNA quantified by quantitative reverse transcriptase PCR in cell lines at basal state and after exposure to CXCL10 (250 ng.mL ${ }^{-1}$ ) (Mann-Whitney test). a, b) H2228; c, d) H322; e, f) H358; g, h) H441; i, j) A549; k, l) H1650. Each sample was assessed in triplicate and the results are representative of three independent experiments. Data displayed as means with SEM indicated by whiskers. *: $p<0.005$; difference between basal state and unstimulated cells. 
in line with these data. KRAS mutations appear to drive IMA and RAS activation is known to modulate CXCL10 and CXCR3 expression in breast cancer [38]. However, there was a lack of correlation between EGFR and KRAS status and the expression of CXCL10 and CXCR3 or co-expression of CXCL10 and CXCR3. This suggests that the CXCL10/CXCR3 pathway is not activated by the EGFR or KRAS driver oncogene. In the studied cell lines, no KRAS- or EGFR-positive cells showed a significant CXCL10-induced up-regulation of CXCR3-A or CXCR3-B.

One mucinous cell line among the three studied up-regulated CXCR3-A mRNA under the effect of CXCL10. A greater number of cell lines representative of mucinous lepidic adenocarcinomas would have improved the robustness of our conclusion. However, only few lung adenocarcinoma cell lines have been identified as originating from lepidic adenocarcinomas ("bronchioloalveolar") [39]. Furthermore, among the studied cell lines, it cannot be excluded that mucinous differentiation may be lost after in vitro passages, thus explaining why the CXCL10/CXCR3-A loop, along with other IMA molecular features, was lost.

Until recently, the CXCR3/CXCL10 axis was considered to exert potent anti-malignancy effects. Our study results were in line with those of a number of other investigations, suggesting this axis has a central role in promoting tumoural capacities depending on CXCR3 splice variant A signalling. Overall, we have hereby provided new insights into the understanding of IMA biology, opening up the possibility of new therapeutic options for this disease known to be frequently multifocal and unresectable at diagnosis.

\section{Acknowledgements}

We would like to thank the Tumorothèque HUEP (AP-HP - GH-HUEP), AP-HP, Hôpital Tenon, Service d'Anatomie Pathologique, F-75970 Paris, France, for providing the samples.

We are also indebted to Laurène Schlick (GRC n04, Theranoscan) for her generous contribution to this work.

\section{References}

1 Curado MP, Edwards B, Shin HR, et al. Cancer incidence in five continents, Volume IX. Lyon, IARC Press, 2007.

2 Travis WD, Brambilla E, Noguchi M, et al. International Association for the Study of Lung Cancer/American Thoracic Society/European Respiratory Society international multidisciplinary classification of lung adenocarcinoma. J Thorac Oncol 2011; 6: 244-285.

3 Garfield DH, Cadranel JL, Wislez M, et al. The bronchioloalveolar carcinoma and peripheral adenocarcinoma spectrum of diseases. J Thorac Oncol 2006; 1: 344-359.

4 Tsuta $\mathrm{K}$, Kawago M, Inoue E, et al. The utility of the proposed IASLC/ATS/ERS lung adenocarcinoma subtypes for disease prognosis and correlation of driver gene alterations. Lung Cancer 2013; 81: 371-376.

5 Warth A, Muley T, Meister M, et al. The novel histologic International Association for the Study of Lung Cancer/ American Thoracic Society/European Respiratory Society classification system of lung adenocarcinoma is a stage-independent predictor of survival. J Clin Oncol 2012; 30: 1438-1446.

6 Yoshizawa A, Motoi N, Riely GJ, et al. Impact of proposed IASLC/ATS/ERS classification of lung adenocarcinoma: prognostic subgroups and implications for further revision of staging based on analysis of 514 stage I cases. Mod Pathol 2011; 24: 653-664.

7 Garfield DH, Cadranel J, West HL. Bronchioloalveolar carcinoma: the case for two diseases. Clin Lung Cancer 2008; 9: 24-29.

8 Breathnach OS, Kwiatkowski DJ, Finkelstein DM, et al. Bronchioloalveolar carcinoma of the lung: recurrences and survival in patients with stage I disease. J Thorac Cardiovasc Surg 2001; 121: 42-47.

9 Ebbert JO, Chhatwani L, Aubry MC, et al. Clinical features of bronchioloalveolar carcinoma with new histologic and staging definitions. J Thorac Oncol 2010; 5: 1213-1220.

10 Casali C, Rossi G, Marchioni A, et al. A single institution-based retrospective study of surgically treated bronchioloalveolar adenocarcinoma of the lung: clinicopathologic analysis, molecular features, and possible pitfalls in routine practice. J Thorac Oncol 2010; 5: 830-836.

11 Carretta A, Ciriaco P, Melloni G, et al. Surgical treatment of multiple primary adenocarcinomas of the lung. Thorac Cardiovasc Surg 2009; 57: 30-34.

12 Daly RC, Trastek VF, Pairolero PC, et al. Bronchoalveolar carcinoma: factors affecting survival. Ann Thorac Surg 1991; 51: 368-376.

13 Volpino P, Cavallaro A, Cangemi R, et al. Comparative analysis of clinical features and prognostic factors in resected bronchioloalveolar carcinoma and adenocarcinoma of the lung. Anticancer Res 2003; 23: 4959-4965.

14 Duruisseaux M, Antoine $\mathrm{M}$, Rabbe N, et al. The impact of intracytoplasmic mucin in lung adenocarcinoma with pneumonic radiological presentation. Lung Cancer 2014; 83: 334-340.

15 Hata A, Katakami N, Fujita S, et al. Frequency of EGFR and KRAS mutations in Japanese patients with lung adenocarcinoma with features of the mucinous subtype of bronchioloalveolar carcinoma. J Thorac Oncol 2010; 5 : $1197-1200$.

16 Wislez M, Antoine M, Baudrin L, et al. Non-mucinous and mucinous subtypes of adenocarcinoma with bronchioloalveolar carcinoma features differ by biomarker expression and in the response to gefitinib. Lung Cancer 2010; 68: 185-191.

17 Finberg KE, Sequist LV, Joshi VA, et al. Mucinous differentiation correlates with absence of EGFR mutation and presence of KRAS mutation in lung adenocarcinomas with bronchioloalveolar features. J Mol Diagn 2007; 9: 320-326.

18 Sakuma Y, Matsukuma S, Yoshihara M, et al. Distinctive evaluation of nonmucinous and mucinous subtypes of bronchioloalveolar carcinomas in EGFR and K-ras gene-mutation analyses for Japanese lung adenocarcinomas: confirmation of the correlations with histologic subtypes and gene mutations. Am J Clin Pathol 2007; 128: $100-108$. 
19 Fernandez-Cuesta L, Plenker D, Osada H, et al. CD74-NRG1 fusions in lung adenocarcinoma. Cancer Discov 2014; 4: 415-422.

20 Goldstraw P, Crowley J, Chansky K, et al. The IASLC Lung Cancer Staging Project: proposals for the revision of the TNM stage groupings in the forthcoming (seventh) edition of the TNM Classification of malignant tumours. J Thorac Oncol 2007; 2: 706-714.

21 Wislez M, Rabbe N, Marchal J, et al. Hepatocyte growth factor production by neutrophils infiltrating bronchioloalveolar subtype pulmonary adenocarcinoma: role in tumor progression and death. Cancer Res 2003; 63: 1405-1412.

22 Lynch TJ, Bell DW, Sordella R, et al. Activating mutations in the epidermal growth factor receptor underlying responsiveness of non-small-cell lung cancer to gefitinib. N Engl J Med 2004; 350: 2129-2139.

23 Yi ES, Chung J-H, Kulig K, et al. Detection of anaplastic lymphoma kinase (ALK) gene rearrangement in non-small cell lung cancer and related issues in ALK inhibitor therapy: a literature review. Mol Diagn Ther 2012; 16: $143-150$.

24 Lazzeri E, Romagnani P. CXCR3-binding chemokines: novel multifunctional therapeutic targets. Curr Drug Targets Immune Endocr Metab Disord 2005; 5: 109-118.

25 Strieter RM, Addison CL, Ehlert JE, et al. Use of immunodeficient mice for the evaluation of CXC chemokines in the regulation of tumor-associated angiogenesis. ILAR J 1999; 40: 175-182.

26 Romagnani P, Annunziato F, Lasagni L, et al. Cell cycle-dependent expression of CXC chemokine receptor 3 by endothelial cells mediates angiostatic activity. J Clin Invest 2001; 107: 53-63.

27 Moriai S, Takahara M, Ogino T, et al. Production of interferon- $\gamma$-inducible protein-10 and its role as an autocrine invasion factor in nasal natural killer/T-cell lymphoma cells. Clin Cancer Res 2009; 15: 6771-6779.

28 Zipin-Roitman A, Meshel T, Sagi-Assif O, et al. CXCL10 promotes invasion-related properties in human colorectal carcinoma cells. Cancer Res 2007; 67: 3396-3405.

29 Murakami T, Kawada K, Iwamoto M, et al. The role of CXCR3 and CXCR4 in colorectal cancer metastasis. Int J Cancer 2013; 132: 276-287.

30 Mulligan AM, Raitman I, Feeley L, et al. Tumoral lymphocytic infiltration and expression of the chemokine CXCL10 in breast cancers from the Ontario Familial Breast Cancer Registry. Clin Cancer Res 2013; 19: 336-346.

31 Ma X, Norsworthy K, Kundu N, et al. CXCR3 expression is associated with poor survival in breast cancer and promotes metastasis in a murine model. Mol Cancer Ther 2009; 8: 490-498.

32 Walser TC, Rifat S, Ma X, et al. Antagonism of CXCR3 inhibits lung metastasis in a murine model of metastatic breast cancer. Cancer Res 2006; 66: 7701-7707.

33 Giuliani N, Bonomini S, Romagnani P, et al. CXCR3 and its binding chemokines in myeloma cells: expression of isoforms and potential relationships with myeloma cell proliferation and survival. Haematologica 2006; 91: 1489-1497.

34 Billottet C, Quemener C, Bikfalvi A. CXCR3, a double-edged sword in tumor progression and angiogenesis. Biochim Biophys Acta 2013; 1836: 287-295.

35 Fulton AM. The chemokine receptors CXCR4 and CXCR3 in cancer. Curr Oncol Rep 2009; 11: 125-131.

36 Mousa HS, Lleo A, Invernizzi P, et al. Advances in pharmacotherapy for primary biliary cirrhosis. Expert Opin Pharmacother 2015; 16: 633-643.

37 Van Raemdonck K, Van den Steen PE, Liekens S, et al. CXCR3 ligands in disease and therapy. Cytokine Growth Factor Rev 2015; 26: 311-327.

38 Datta D, Flaxenburg JA, Laxmanan S, et al. Ras-induced modulation of CXCL10 and its receptor splice variant CXCR3-B in MDA-MB-435 and MCF-7 cells: relevance for the development of human breast cancer. Cancer Res 2006; 66: 9509-9518.

39 Phelps RM, Johnson BE, Ihde DC, et al. NCI-Navy Medical Oncology Branch cell line data base. J Cell Biochem Suppl 1996; 24: 32-91. 